\title{
Nudges, Regulations and Liberty
}

\author{
Keith Dowding ${ }^{1}$ (D) and Alexandra Oprea ${ }^{2 *}$ \\ ${ }^{1}$ Australian National University, Australia and ${ }^{2}$ University of North Carolina at Chapel Hill, USA \\ ${ }^{\star}$ Corresponding author. Email: alexandraroprea@gmail.com
}

(Received 19 May 2021; revised 19 August 2021; accepted 24 November 2021; first published online 31 January 2022)

\begin{abstract}
Nudge advocates contend that nudges are liberty preserving, while government regulations are not. We interrogate that assumption by considering negative liberty in the forms suggested by the proponents of nudges. Specifically, we examine three ways of measuring negative liberty - liberty as freedom of choice, liberty as absence of coercion and liberty as absence of interference - applying the measures to a case study relevant to the nudge literature: regulations governing healthy food manufacture. We show that, depending on the liberty measure adopted and the estimated impact on producer and consumer behaviour, some regulations can be liberty reducing, while others are liberty preserving or liberty enhancing. When it comes to comparing nudges and more traditional policies aimed at increasing the health and welfare of citizens, there is no a priori negative liberty ground for preferring nudges.
\end{abstract}

Keywords: nudge; regulation; liberty; freedom of choice; public health

Carolyn is the director of food services for a large, multi-site private company serving food to thousands of employees every day. She can dictate policy to the directors of the firm's cafeterias in the numerous sites she manages. This is a variant of the set-up for a nudge proposed by Thaler and Sunstein $(2008,1-3)$ :

Cafeteria Nudge: Without changing the menus, Carolyn instructs directors of her company's cafeterias to change the layout of the cafeterias. The healthy foods are now presented at eye level to catch the attention of the customers. The unhealthy foods are now displayed less prominently.

Compare this nudge to the following two alternatives relying on more traditional regulatory mechanisms:

Cafeteria Tax and Subsidize: Carolyn instructs directors of her company's cafeterias to change the prices of the foods being served. She 'taxes' unhealthy foods to make them more expensive and 'subsidizes' healthy foods to make them cheaper.

Cafeteria Healthier Menu: Carolyn instructs directors of her company's cafeterias to change the menu being offered to the customers. The unhealthiest items are removed from the menu (for example sugar-sweetened beverages (SSBs), especially sodas; snacks with extremely high sugar, salt, and trans-fat content such as potato chips and pizza). Some healthy items are added to the menu (for example fruit and vegetables packaged as snacks; meals with higher nutritional value). 
According to Thaler and Sunstein, the advantage of the Cafeteria Nudge over regulatory approaches, such as Cafeteria Tax and Subsidize and Cafeteria Healthier Menu, is that it improves consumers' welfare without reducing liberty. ${ }^{1}$ In this article, we challenge this claim by examining how these different alternatives affect liberty under different conceptions of how negative liberty might be measured. When comparing nudges with more traditional policies aimed at increasing the health and welfare of citizens, there is no a priori negative liberty ground for preferring nudges. One of the lessons of our article is that the liberty-preserving credentials of policies need to be subjected to careful empirical liberty assessments analogous to cost-benefit analyses in the realm of welfare.

The last decade has seen an explosion of interest in nudge among both academics and political actors. 'Nudge units' have become a staple of government policymaking, starting with the recruitment of Cass Sunstein (co-author of Nudge) to the US Office of Information and Regulatory Affairs in 2009 and the founding of the UK Behavioural Insights Unit (BIU) in 2010 (Halpern 2015). The Organisation for Economic Co-operation and Development (OECD 2017) reports over 200 public entities applying behavioural insights globally. Given its political significance, it is important to be clear about the normative criteria employed when assessing the comparative advantage advocates claim nudge has over more traditional government tools, such as regulations, taxation and spending.

Our article proceeds in six sections. The first section introduces the primary ways in which participants in the nudge debate have defined liberty. The second section then turns to the literature on the measurement of freedom, identifying the primary ways in which liberty in the nudge tradition can be quantified. In the third section, we introduce the principal examples of regulations that address the public health crisis caused by growing rates of obesity, diabetes and heart attacks. The fourth section provides a systematic assessment of our examples with respect to their effect on liberty, measured in the ways described in the first and second sections. We show that assessing the effects of specific regulations on freedom involves difficult but tractable empirical issues. The fifth section responds to objections. The sixth section concludes with methodological and substantive lessons for the ethics and politics of nudge, and of regulation more broadly.

\section{Nudges and Liberty}

We are not the first to scrutinize Thaler and Sunstein's claims about the consequences of nudges for consumer liberty. However, our approach differs in two main ways. First, we focus on a systematic comparison between nudges and regulations, rather than considering nudges in isolation or in comparison with unregulated markets. Secondly, we restrict our focus to measures of negative liberty.

Many previous accounts concentrate upon 'positive liberty' in terms of autonomy or upon 'republican liberty', rather than 'negative liberty' in terms of freedom of choice, non-coercion or freedom from interference. These critics suggest nudges reduce liberty because they manipulate subjects, thereby reducing subjects' autonomy (Grüne-Yanoff 2012; Hausman and Welch 2010; Rebonato 2014), or 'shape' choice by bypassing rational or deliberative capacities (Bovens 2009; Hausman and Welch 2010; White 2013; Wilkinson 2013). ${ }^{2}$ This leads to concerns

\footnotetext{
${ }^{1}$ In this article, we are primarily concerned with the liberty consequences for consumers, rather than for producers or sellers. The examples discussed by Thaler and Sunstein usually constitute nudges only for consumers, who can opt out or ignore the nudge. They represent regulations as far as producers or sellers are concerned, making it impossible to assess whether nudges have a liberty advantage over regulations in the case of producers. Consider, for example, the requirements for restaurants to list calories on menus or Carolyn's directives to cafeteria staff. Although we do consider some of the implications of nudges and regulations for producers in the fifth section later, we leave a fuller discussion of this for future work.

${ }^{2}$ Some libertarian critics of nudging, such as Rebonato (2014) and Grüne-Yanoff (2012), do consider some versions of negative liberty, but they do not provide a systematic comparison between nudges and regulations, and instead focus on comparing nudges to unregulated markets.
} 
that nudges can reduce citizens' decision-making capacities (Bovens 2009; Button 2018; John, Graham and Stoker 2009; Rebonato 2014; Waldron 2014). ${ }^{3}$ All of these claims about the potential liberty-reducing effects of nudges fit into the broadly positive account of liberty in terms of autonomy and rational deliberation (Berlin 1995b; Carter 2021). In a similar vein, some suggest that nudges reduce choosers' republican liberty through domination or 'alien control' (Goodwin 2012; Grüne-Yanoff 2012). ${ }^{4}$

Positive and republican conceptions of liberty are certainly important in all-things-considered assessments of whether nudges promote liberty more than traditional regulatory tools. However, avoiding negative liberty measures has limited the scope of the critique of nudge. Instead of challenging the liberty advantage of nudges over regulations, these critics have limited themselves to challenging the positive or republican liberty advantage of nudges. This is unfortunate because negative liberty conceptions are important and valued across a range of liberal and democratic theories. They are also highly valued by the proponents of nudge, who have repeatedly gone back to argue that nudges retain a negative liberty advantage over regulations (Schmidt 2017, 404).

Thaler and Sunstein $(2008,5)$ describe nudges as 'liberty-preserving', contrasting them with liberty-reducing traditional regulatory tools. Although they never provide a systematic definition of liberty, they primarily invoke: (1) freedom of choice; and (2) absence of coercion. They also mention liberty as (3) freedom from interference, though they display some reservations about this conception. We analyse the effects on liberty under all three negative liberty accounts.

Thaler and Sunstein generally view liberty in choice terms: 'We strive to design policies that maintain or increase freedom of choice' (Thaler and Sunstein 2008, 5). They specify that 'choices are not blocked, fenced off, or significantly burdened', that nudges operate 'without forbidding any options or significantly changing their economic incentives', and that nudges are 'easy and cheap to avoid' (Thaler and Sunstein 2008, 5, 6). Keeping alternatives intact distinguishes Cafeteria Nudge from what they call 'mandates' of the kind employed in Cafeteria Healthier Menu: 'Nudges are not mandates. Putting the fruit at eye level counts as a nudge. Banning junk food does not' (Thaler and Sunstein 2008, 6). This comparison implies that more traditional government regulations necessarily reduce freedom of choice. It is precisely this assumption that we challenge.

Appealing to libertarians, Thaler and Sunstein also claim nudges are not coercive: 'If no coercion is involved, we think that some types of paternalism should be acceptable to even the most ardent libertarian.' (Thaler and Sunstein 2003, 175; see also Sunstein and Thaler 2003, 1159; Thaler and Sunstein 2008, 11). Again, they do not provide an account of what counts as coercion, but simply mention mandating certain behaviours, such as organ donation or charitable giving (Sunstein and Thaler 2003, 1193), and forcing someone to choose rather than providing a default option (Sunstein and Thaler 2003, 1173). Emphasizing the non-coercive manner of nudges highlights their assumption that other regulatory tools are necessarily coercive (Thaler and Sunstein $2008,14)$, something we consider in some detail.

Thaler and Sunstein $(2003,176)$ themselves acknowledge that a common libertarian way of thinking about liberty is the 'assumption that individual choices should be free from interference', but they do not explicitly discuss this account. They suggest that some interference with liberty is inevitable and seem to assume that maximizing such negative liberty entails minimizing all human constraints. However, as we see later, that is not how the most-sophisticated approaches

\footnotetext{
${ }^{3}$ Few of these authors, however, are sufficiently explicit about the baseline relative to which liberty is reduced. For many, the baseline seems to be the ideally autonomous agent, without necessarily considering the comparative institutional analysis we are concerned with (see Dowding and Oprea 2021). For others, there are occasional comparisons to minimally regulated markets or real-world examples of regulations. One of the contributions of our article is to offer a more systematic comparison between nudges and regulations on liberty grounds.

${ }^{4}$ To the extent that democratic government is in the control of citizens, then government nudges would not be liberty reducing on a republican account of liberty (see Schmidt 2017).
} 
measure negative liberty. We consider freedom from interference in some detail in order demonstrate that under any broadly negative account of liberty, nudge is not necessarily liberty neutral and regulations are not necessarily liberty reducing. Only by considering the most-used libertarian conception can we actually address Thaler and Sunstein's claims.

\section{Measuring Negative Liberty}

Having identified the three most relevant notions of negative liberty - (1) freedom of choice, (2) absence of coercion and (3) freedom from interference - we present some of the key proposals for measuring liberty under each conception. None of the three conceptions is as simple to measure as the nudge advocates suggest. In each case, measuring the degree of liberty requires both conceptual decisions about what precisely is measured (for example, the number of options, diversity of options or preference or value-weight of options) and extensive empirical information about the consequences of a given regulation.

\section{Liberty as Freedom of Choice}

The voluminous axiomatic-deductive literature on measuring freedom of choice demonstrates the various issues that arise (for a review, see Dowding and Van Hees 2009). ${ }^{5}$ The simplest measure of freedom of choice is the 'cardinality rule', which naively suggests that the greater the number of items in an individual's opportunity set, the larger their freedom of choice (Pattanaik and Xu 1990; Pattanaik and Xu 1998). The opportunity set represents the (finite) set of mutually exclusive options from which the individual can choose, with the options representing available courses of action, bundles of consumption goods or other relevant aspects of choice. The size of the opportunity set will be constrained by, among other things, the individual's financial circumstances.

The cardinality rule assigns the same weight to each item in the opportunity set and calculates freedom of choice as the total number of items in the set. It is subject to obvious objections. The first is that it entails that a large opportunity set comprising many almost identical items offers more freedom of choice than one with fewer but more varied items. Call this the 'diversity objection'. Secondly, it entails that an opportunity set with many low-valued items offers more freedom of choice than one with fewer but highly valued ones. Call this the 'value objection'. The response to the first objection is to add some element of diversity to the measurement of freedom, for example, rank opportunity sets by similarity-based partitions (Pattanaik and Xu 2000), by their most-dissimilar pair of alternatives (Bervoets and Gravel 2007) or by multi-attributes (Nehring and Puppe 2002; for a review, see Nehring and Puppe 2009). The response to the second objection is to suggest that we must add some element of value, for example, rank opportunity sets by the level one can expect an individual to achieve with this set (Arrow 1995; Kreps 1979) or by some objective criterion (Sen 2002).

Both routes seem plausible, though the axiomatic-deductive literature points to various problems with each. When it comes to diversity, it turns out that measures tend to lead to either the diversity or the cardinality aspects dominating (Van Hees 2004). The dominance of diversity can lead to implausible consequences, such as a choice between an extreme left-wing and an extreme right-wing party giving more freedom than the choice of numerous parties closer to the centre (Dowding and Van Hees 2009). The dominance of cardinality returns us to the original concerns about diversity. For example, an individual might implausibly be seen as having more freedom of choice when offered many flavours of soda than when offered fewer but more diverse options (for example, water, soda, juice and wine). When it comes to adding values, whether objective or subjective, there is a danger that the measurement of liberty degenerates into a

\footnotetext{
${ }^{5}$ By 'axiomatic-deductive', we mean approaches based upon social choice and decision- and game-theoretic analyses.
} 
measure of welfare, either objectively characterized or through subjective utility (Dowding and Van Hees 2009).

Later, in the fourth section, we examine regulation and nudges in terms of naive cardinality, including consideration of the diversity of alternatives in an opportunity set (diverse freedom of choice) and subjective evaluation of the alternatives (evaluative freedom of choice). We only consider subjective utility since that is how welfare is seen in the nudge literature (Schmidt 2017, 405). Where relevant, we consider subjective value under two interpretations: revealed preference and stated preference.

\section{Liberty as Absence of Coercion}

There are several approaches to analysing coercion (for an overview, see Anderson 2011). In this article, we focus on a dominant understanding of coercion that argues that A coerces B to do $x$ if and only if: (1) A's proposal creates a choice situation for B such that B has no reasonable alternative but to do $x$ (the choice prong); and (2) it is wrong to make such a proposal to $\mathrm{B}$ (the proposal prong) (Wertheimer 1987, 172). ${ }^{6}$ We chose this definition for its ability to address both public and private instances of coercion. ${ }^{7}$ Given that the state has the ability to make non-compliance with its regulations costly in ways that can satisfy Condition 1, whether a given regulation constitutes coercion will largely depend on whether Condition 2 holds.

One fault line in different conceptions of coercion is over how we distinguish which proposals are wrong by being coercive threats (for example, 'Give me your wallet or I will shoot you') and which are non-coercive offers (for example, 'I will pay you a fee if you provide a service') since both change an individual's opportunity set. Nozick (1969) demonstrates the need for some moral baseline to distinguish threats from offers since different baselines give different ideas of what constitutes a threat and an offer. In his example, a slave is regularly beaten by his master. One day, the master says he will not beat the slave today if the slave performs some act. If we take the baseline as the 'normal course of events', then in promising not to beat the slave, the master is making an offer since if the slave complies, he will be better off than he would be in his usual situation. However, the slave's normal situation might not constitute the right kind of baseline for considering what constitutes coercion. People should not be beaten; hence, the offer not to beat as long as the slave complies constitutes a threat. Most accounts of coercion assume there should be a moral baseline for distinguishing threats and offers. Proposals violating B's moral or legal rights, for example, constitute threats (for example, proposing not to take B's rightful property). Morally permitted proposals to B constitute offers (for example, proposing to give B a better-paid job).

A second question concerns the number of actions with respect to which an agent is coerced, which depends on those actions' specification. We might say a person is free to do $x$ if, and only if, no one deliberately makes it impossible or poses a threat for them to do or not do $x$. Whether the individual is coerced by a given regulation depends on the way in which $x$ is defined. For example, a regulation banning certain items from a given cafeteria makes it impossible for a consumer to purchase those specific items at that cafeteria. If $x$ is defined as 'purchasing good $y$ at location $z$ ', then the policy change coerces the consumer. If $x$, however, is defined as 'purchasing good $y^{\prime}$, then the change in policy at the cafeteria does not coerce the consumer since they can

\footnotetext{
${ }^{6} \mathrm{We}$ leave aside approaches to coercion that depend on violations of neo-Kantian autonomy for examination in a companion article concerning nudge and manipulation (Dowding and Oprea 2021).

${ }^{7}$ Some believe that all state policies are coercive because they are backed by the use of force. If that is the case, all regulations are necessarily coercive (even when legitimate). On this understanding of coercion, all public nudges are coercive. Producers are coerced into including warnings on cigarette packages and calorie counts on menus. Citizens objecting to pictures of flies drawn on urinals or closer lines on highways would face legal sanctions if they attempted to remove the nudge. We therefore believe that it is better to avoid blanket classifications of state action as coercive even if prominent political philosophers such as Rawls or Dworkin have chosen to employ them.
} 
purchase the item elsewhere. Under very narrow specifications, such as 'purchasing good $y$ at location $z$ without making any supplementary effort to obtain it', nudges changing product location are similarly coercive. One concern with such narrow specifications is that it labels as coercive trivial changes in opportunity sets. For example, a supermarket changing the stock of cereal brands would count as coercive. One solution, similar to the case of freedom of choice, is to add considerations of value to the equation, counting only those items that the person deems particularly valuable.

\section{Liberty as Freedom from Interference}

While libertarians celebrate freedom of choice and are opposed to coercive government, freedom from interference is often their defining notion of liberty. Libertarians generally want to maximize liberty. Whereas the axiomatic-deductive approach examines such maximization in terms of the number of alternatives in an opportunity set, freedom from interference is defined in terms of the constraints upon what people can do due to the actions of others. Robinson Crusoe, when all alone on his island, is not constrained by anyone else and so enjoys full negative liberty. However, there might not be much he can do, stranded on a desert island. His only options might be sunbathing or shading while starving to death. Friday's arrival enables him to do more things, even though Friday can now constrain him in some activities. So, Crusoe can now do more but is also constrained more.

Measures of such negative liberty normally take into consideration both what people can do and what they are constrained from doing by others (Carter 1999; Kramer 2003; Steiner 1983). These measures therefore count both potential actions (freedoms) and constraints on potential actions (unfreedoms). Clearly, any constraint constitutes some reduction in liberty. It ends what Carter (1999) calls a 'specific liberty'. Any interference that makes some alternative (effectively or reasonably) impossible constitutes a loss of specific liberty. Thus, any regulation banning an item or making an item more expensive through taxation ends a specific liberty. However, this is a trivial notion of reducing liberty since it means that any such action reduces liberty. What matters for maximizing liberty is whether an individual's overall liberty has increased or decreased. For example, a traffic light ends a person's specific liberty to cross a junction at a given time $t_{1}$ when the light is at red but, if the lights enable traffic to flow more freely, increases that person's overall liberty to pass the junction more often and more quickly. While regulations always reduce some specific liberties, they often enable people to do many other actions without the loss of conjunctively exercisable liberties. Overall, such laws increase such negative liberty.

Both Carter (1999) and Kramer (2003) produce measures of this form of negative liberty. Carter defines a person's overall degree of freedom as the ratio of the total number of acts the individual is free to perform to the total number of acts the individual is either free or unfree to perform. This ratio has an upper bound of 1 - the case of Robinson Crusoe before Friday arrives. Kramer adopts the same definition, except that he weighs each freedom and unfreedom by how valuable they are to the individual, so that individuals with more valuable options are generally freer. The details do not matter outside of considerations of what weighting items entails for our toy cases.

\section{Key Example: Regulations in Public Health}

We focus on public health, particularly the current obesity crisis, as an area receiving significant attention from nudge advocates. To demonstrate their urgency, we provide a brief review of the problems along with regulatory solutions.

Obesity has become a major problem in the developed world. In the United States, obesity (Body Mass Index [BMI] > 30) increased annually between 1960 and 1980 by about 1.3 per cent to about 15 per cent of the population and has now more than doubled to around 35 per 
cent, with an annual rate of increase of 4.7 per cent. Grade III obesity (BMI $>40)$ has grown even faster. Health problems associated with obesity - such as type 2 diabetes, various forms of cancer, heart disease, musculoskeletal disorders, sleep apnoea and gallbladder problems - together account for around 400,000 deaths each year. In the UK, 28 per cent of the population are considered obese, with another 35 per cent overweight (BMI $>25)$. Obesity is estimated to reduce life expectancy by around two years and life expectancy for those with a BMI over 40 by eight to ten years. The estimated costs to the National Health Service are about $£ 5$ billion per annum, with economic costs overall to the nation of around $£ 27$ billion (see Dowding 2020, ch. 3 ).

Developing countries are seeing similar increases. The worst affected are populations in the Pacific Islands, with 43 per cent of Cook Islanders, 41 per cent of French Polynesians and 79 per cent of the population of Nauru having a BMI in excess of 30 (Prentice 2006). Globally, more than 1.9 billion adults (39 per cent of world population) were overweight in 2016. Of these, over 650 million were obese. The worldwide prevalence of obesity tripled between 1975 and 2016, affecting both adults and children. In 2016, 6 per cent of girls and 8 per cent of boys are obese, up from under 1 per cent in 1975 (WHO 2020a; WHO 2020b).

The US increase in obesity correlates with a 12 per cent increased caloric intake between 1985 and 2000, largely due to the increased consumption of grains, added fats and sugars mostly due to canned fruit and SSBs. High caloric intake is associated with SSBs not only because they are highly calorific, but also because they give heightened sweet alertness to frequent consumers, who then consume greater quantities of high-calorie solid food (Caprio 2012). There are also replacement effects with SSB consumers drinking less water and milk, and eating less fresh fruit (Schmidt 2014).

Why is there increased consumption of SSBs and highly processed foods? There are two reasons: first, they are more readily available; and, second, their price has dropped enormously relative to healthy food. While the price of food overall fell by around 15 per cent, the price of fresh fruits and vegetables rose by 118 per cent, fish by 77 per cent, and dairy products by 56 per cent (Dowding 2020, 56). Decreasing food costs are explained by big falls in meat, pre-packaged and prepared foods, and soft drinks.

Governments try to persuade people to eat more healthily with campaigns and often require producers to list ingredients, including salt and sugar content, in packaged food. Restaurants are asked or required to display the calorie content of menu items. One nudge idea is to place healthy items at eye level, as in the Cafeteria Nudge example earlier. ${ }^{8}$ Regulations around the world include: (1) restrictions on additives; (2) taxes on additives; and (3) subsidies for healthier purchases.

Regulations focus on limiting dangerous additives: trans fats (especially partially hydrogenated oils), sodium and sugar. Several countries ban or limit the amount of trans fats permitted in manufactured food. In 2003, Denmark became the first country limiting it to 2 per cent of fats and oils. The US Food and Drug Administration deemed trans fats unsafe in 2015, giving food manufacturers three years to comply with a ban (US Food and Drug Administration 2018). The World Health Organization (WHO 2019) has pushed for further restrictions.

Unlike trans fats, only excess consumption of sugar and sodium is unhealthy, making restrictions harder to implement. Restricting the sodium and sugar content of food served in institutions such as schools, hospitals, care facilities and prisons is one route. In the United States, Hawaii, Massachusetts and Washington, DC, for example, limit sodium content in food provided or sold in schools (National Conference of State Legislatures no date). Such regulations could be expanded to other institutions and restaurants.

Taxes and subsidies provide another mechanism for dealing with excess consumption. Several countries tax high-sugar foods, particularly SSBs. Mexico was the first to levy SSB taxes in 2014.

\footnotetext{
${ }^{8}$ There is no requirement for supermarkets to place healthy food at eye level; indeed, food manufacturers negotiate deals with supermarket chains for optimal placement of their products, known as 'slotting' (Rivlin 2016).
} 
By mid-2019, forty-two countries and seven US cities had implemented SSB taxes (Grummon et al. 2019). Studies demonstrate that such taxes reduce consumption of SSBs across all socio-economic groups (Backholer et al. 2016). Hungary introduced a public health product tax on foods high in sugar, salt and stimulants (of the kind found in energy drinks) in 2011 (Bíró 2015).

Most attention is on taxes, but there are also subsidies for healthy food, usually targeting lower-income consumers, who are also at highest risk of obesity, diabetes and heart disease. Seattle's Fresh Bucks programme provides a dollar-for-dollar matching for federal-governmentprovided Supplemental Nutrition Assistance Program (SNAP) benefits at farmers' markets up to US\$10. In South Africa, the largest private insurer (Discovery Health) started a HealthyFood programme in 2009 , entitling members to a 10 per cent rebate on healthy foods and up to a 25 per cent rebate upon completion of an online health risk assessment questionnaire (Sturm, An, and Patel 2013).

\section{Assessing the Effects on Liberty}

In this section, we consider the effects of nudges and regulations on liberty, beginning with the three cafeteria examples. These stylized examples follow the main policy implementation strategies presented in the third section but do not enter into the complicated issues of strategic behaviour on the part of producers, short- v. long-term effects and other complexities that come from the national-level limits and taxes on additives, which we leave for the fifth section. Even with our toy examples, assessing the actual effects on liberty is not straightforward. We cannot simply assume that regulations are liberty reducing while nudges are liberty preserving.

\section{Freedom of Choice}

We begin with freedom of choice under the naive cardinality rule, then take cardinality with diversity (diverse freedom of choice) and finally cardinality with subjective value (evaluative freedom of choice). In each case, we define the opportunity set as the finite set of mutually exclusive bundles of foods and beverages that constitute a lunch. The cafeteria is assumed to offer multiple lunch options, some are healthier and some less healthy. Everyone is assumed to have a fixed lunch budget that determines the upper limit of spending on a given lunch.

In Cafeteria Nudge, under naive cardinality, the number of alternatives in a given consumer's opportunity set does not change, only the manner in which they are displayed. Hence, as Thaler and Sunstein maintain, it has no effect on consumers' freedom of choice. Since the number of options is unaffected, there is also no effect on diverse or evaluative freedom of choice. Of course, assuming nudge changes what people choose from the menu, the utility from lunch changes. However, this has no effect on freedom of choice, which is concerned not with the utility associated with the alternative actually chosen, but with the evaluation of the menu of alternatives. We return to this point later.

Cafeteria Tax and Subsidize posits that Carolyn alters the prices of healthy and unhealthy items in order to equalize their relative prices, using revenue from taxation to subsidize healthier products. Under the naive cardinality rule, the effect on freedom of choice of Cafeteria Tax and Subsidize depends on the precise choice of policy and the budget of each consumer. To simplify things, assume that the cafeteria only offers the following three lunch options: A (cup of soup, roast chicken with vegetables and water) at $\$ 15$; B (fries, cheeseburger and soda) at $\$ 12$; and C (kale salad, grilled salmon with rice and kombucha) at $\$ 18$. Suppose that Carolyn's tax-and-subsidize policy taxes the unhealthy burger meal and subsidizes the healthier chicken meal, so that the new prices are $\$ 12$ for A, \$15 for B and \$18 for C. Given that the new policy keeps the same range of prices but switches them between the healthy and unhealthy options, there is no effect on naive cardinality. 
However, now suppose that Carolyn's tax-and-subsidize policy produces the following new prices: $\$ 15$ for A, $\$ 15$ for B and $\$ 15$ for C. For consumers whose lunch budget was $\$ 18$ or higher, the new policy has no effect on freedom of choice measured as naive cardinality. For consumers whose lunch budget was $\$ 15$, the new policy increases their freedom of choice, as it adds a healthy option to their opportunity set. For consumers whose lunch budget was $\$ 12$, the new policy reduces freedom of choice since they now have zero items in their opportunity set. The overall social effect on cardinality will depend on the distribution of consumers across these categories. The effect on diverse freedom of choice is similarly open-ended: the first price policy has no effect on the opportunity set and therefore no effect on diversity; the second policy has heterogeneous effects for the different consumers.

Does Cafeteria Tax and Subsidize increase or reduce freedom of choice under the subjective evaluation addition to the cardinality rule? The answer depends on whether we rely on revealed or stated preferences. Since our goal is to compare like with like, we rely on the same measure as the nudge advocates. According to Thaler and Sunstein $(2008,7)$, the high rates of obesity, combined with people's willingness to pay third parties to help them lose weight, make it implausible to assume that people are choosing a diet that they prefer over alternatives. The National Health and Nutrition Examination Survey conducted between 2013 and 2016 in the United States reported that 67 per cent of obese adults and 49 per cent of overweight adults attempted to lose weight during the previous 12 months (Martin et al. 2018). A 2016 survey by the Pew Research Center found that 72 per cent of Americans believe that healthy eating habits are very important for a person's chances of living a long and healthy life and that 58 per cent of US adults say that they should be eating healthier than they currently do (Funk and Kennedy 2016) and are prepared to pay more for healthy food (Steingoltz, Picciola, and Wilson 2018). These surveys therefore seem to suggest that we should rely on people's stated preferences for being healthy over the evidence of their diet.

The alternative draws on revealed preference evidence. Even if people say they prefer eating healthier foods, the fact that they choose unhealthy foods under normal market conditions reveals their true valuation. However, choice only reveals preferences under the conditions in which it is made. If people tend to choose $x$ over $y$ under X conditions and $y$ over $x$ under Y conditions, then that choice reveals only that they prefer $x$ over $y$ under $\mathrm{X}$ conditions and $y$ over $x$ under $\mathrm{Y}$ conditions. Choosing unhealthy over healthy food when the former is at eye level and healthy over unhealthy food when healthy food is at eye level reveals that people tend to choose food placed at eye level. The standard examples of preference reversal show that we prefer an item when it is described in one manner rather than another. Revealed preference analysis therefore only shows that we prefer one description over another. Applied to our cafe examples, it shows that we tend to choose what happens to catch our eye first, unless we have a strict preference for something else. In revealed preference terms, we are only likely to have a weak preference for $x$ over $y$, or $y$ over $x$, which is easily overwhelmed by the placement. ${ }^{9}$ Given that the revealed preference evidence over the absolute preference seems insecure in such cases, stated preference evidence seems to be decisive over the character of 'true' preference.

Stated preference evidence suggests that taxing unhealthy food and subsidizing healthier alternatives will make higher-valued products cheaper and lesser-valued ones more expensive. Thus, by the assumptions underlying the nudge programme, Tax and Subsidize will increase evaluative freedom of choice. At least, it will increase it on average. Those with a strict preference for the taxed unhealthy food might lose evaluative liberty. For some, it will increase evaluative freedom of choice, while for others, it will decrease it. This also happens in many market settings, for example, there are loss leaders where supermarkets recoup their profit margins by what they

\footnotetext{
${ }^{9}$ Of course, where someone displays a weak preference for $x$ over $y$, or for $y$ over $x$, we infer indifference (see, for example, Austen-Smith and Banks 1999, ch. 1).
} 
charge on other items. In like-for-like comparisons, however, by assumption, the social evaluative freedom of choice over society as a whole has increased.

Now, it might be objected that in our toy tax-and-subsidize example, the scheme is perfectly efficient, that is, no money is lost in the process as the size of the subsidy matches the size of the tax. Such efficiency is rare in the real world, and highly targeted taxes tend to be expensive to administer. This means that the size of the subsidy would typically be smaller than the tax, especially if the government creams off some of the tax for other purposes. We might therefore be sceptical about the liberty-preserving claims of tax-and-subsidize naive cardinality and increasing liberty under evaluative freedom of choice. What this objection does, however, is to point to how important the specifics of cases are when it comes to such liberty calculations. It does not establish an a priori case for nudge.

Healthier Menu removes items from the menu. It therefore alters the opportunity set of the customers. However, by assumption, they are replaced with healthier alternatives. Under the naive cardinality rule, freedom of choice is not affected. It is not straightforward whether liberty in terms of cardinality and diversity has been reduced or increased. As intimated in the second section, measuring diversity is not straightforward and, in part, will depend on the dimension of diversity we are considering. For example, if the diversity was 'range of healthiness of foods', then removing the unhealthiest ones decreases diversity, unless even more healthy ones at the other end of the spectrum keep the diversity score identical. However, 'scope of healthiness' is probably not the range of diversity we consider important. Rather, it would be types of food or range of flavours. If diversity is the key freedom of the value of choice, then Carolyn could attempt to create a more diverse set of foods.

Unregulated markets sometimes produce a Hotelling effect, where choice becomes constrained as competitors aim to capture the peak of demand by catering to the preferences of the modal consumer. In the case of soda, for example, this leads to less diverse flavours. Indeed, to gourmets, manufactured food tastes much the same, whereas carefully prepared fresh foods have a much wider diversity of flavours and tastes. We will not make the claim based on such abstract reasoning that Healthier Menu necessarily increases diverse freedom of choice, but we do claim that it does not necessarily reduce it. This is an empirical question that depends upon what is offered under the two comparators and upon our measure of diversity.

Much the same analysis applies to Healthier Menu for the cardinality with subjective evaluation as to Tax and Subsidize, though the revealed preference objection carries more weight there than with Healthier Menu. Under the nudge assumption that people prefer the healthier options, the healthier menu - as long as it provides at least as wide a variety of foods - should not reduce evaluative freedom of choice. ${ }^{10}$ The caveat is that individuals cannot reveal preferences for products that Carolyn bans. Of course, under the former regime they could not reveal preferences for healthier snacks if these were not available. Nevertheless, the argument for markets is precisely that they allow preference revelation for products that regulated market systems do not allow. The Hotelling effect that might reduce diversity is, after all, caused by trying to gain the peak subjective revealed preference. Indeed, given the potential loss of evaluative freedom if tax-and-subsidize is inefficient, then banning some types of food, forcing producers to create healthier options, might, in evaluative freedom of choice terms, increase liberty, or at least be more liberty preserving than tax and subsidize. What we can confidently conclude is that we cannot simply assume in a specific cafe that Healthier Menu necessarily reduces evaluative freedom of choice based upon stated preferences. It depends on the offerings and the values of the customers.

\footnotetext{
${ }^{10}$ In this case, we are assuming that individuals genuinely prefer the healthy foods. However, it is possible for consumers to prefer being healthy while also preferring junk food. While irrational, such preferences are nonetheless consistent with the survey findings that individuals prefer being healthy. In these cases, one would have to determine which preference is the strongest for the purpose of measuring evaluative freedom of choice.
} 
However, this does not mitigate the general argument that a major justification for markets is that they enhance freedom of choice. Of course, that justification does not merely hold for cardinality with subjective evaluation, but also for encouraging diversity of options and naive cardinality. Overall, that is certainly so, though it is not always true for particular products. The SSB story is an example of market competition driving out diversity. We cannot simply assume that unregulated markets provide optimal choice.

\section{Freedom as Absence of Coercion}

Is regulation coercive? Cafeteria Nudge does not seem to be coercive for consumers by Wertheimer's two criteria of (1) no reasonable alternative and (2) making a morally wrong proposal. ${ }^{11}$ First, since no alternatives are removed, if consumers do not want the items at eye level, they can relatively easily choose something else. This is why Thaler and Sunstein emphasize the fact that nudges are cheap and easy to avoid. Secondly, rearranging items does not seem to violate any consumer rights. Although this might seem to constitute an advantage for nudges, it is worth noting that coercion requires that both Conditions 1 and 2 be satisfied.

Cafeteria Tax and Spend and Cafeteria Healthier Menu certainly affect the choice prong, but that is only coercive if it forces consumers to fall beneath the relevant moralized baseline. In the private market case, we cannot assume that whenever a seller replaces one item with another, they are coercing their customers. Neither should we assume it in the case of changes in regulations.

However, if we are discussing state regulation, then perhaps we cannot be so dismissive. If we accept that the morally correct baseline is the free market without any state intervention, then any intervention - including nudge - is coercive. Nudge advocates might think the correct baseline is the free market without any state intervention other than nudges, which is surely question begging without further argument, again suggesting that there is no a priori argument for preferring nudges to regulation.

More pertinently to our comparison of nudges and regulation, if one takes the line that state actions are always coercive, as some do, then nudges are coercive, as are regulations. It might be argued that regulations are more coercive since they remove alternatives where nudges do not. However, it still needs to be established that removing alternatives is coercive by Wertheimer's account. Replacing one alternative with another is not the same as leaving no choice, so arguably does not break the choice prong. Even if the choice prong is said to be broken, one still needs to establish that such regulations break the proposal prong by making morally wrong proposals. It is not obvious that regulations against unhealthy food are morally wrong. One needs a specific argument about the moral wrongness of any given regulation, especially given the opportunity sets of diverse citizens. In Cafeteria Healthier Menu, only if the unhealthy menu is thought to be the morally correct baseline is Carolyn's directive coercive.

\section{Liberty as Freedom from Interference}

In order to consider freedom from interference, we need to consider not only the items in the opportunity set, but also those excluded from the opportunity set or made prohibitively expensive. We can assume that the effects on the items in the opportunity set for freedom from interference remain the same as for freedom of choice under the cardinality, diversity and subjective evaluation variants. That is to say, the 'positive' side of freedom from interference remains the same as it does for freedom of choice. It is only the 'negative' side of freedom from interference - what is not in the opportunity set due to the actions of other human agents - that requires separate analysis.

\footnotetext{
${ }^{11}$ Our focus in this article is the liberty of consumers. However, it is worth noting that both nudges and regulations remove options from the producers' opportunity sets by constraining the manner in which items are displayed or forcing them to provide information to consumers.
} 
For Cafeteria Nudge, nothing is strictly excluded. At most, changing the positioning of items affects the time it takes to come to a decision. Hence, it has no effect on freedom from interference even though it does not offer items that exist in Cafeteria Healthier Menu. Cafeteria Tax and Subsidize may or may not exclude any items for a given consumer, depending on their budget. If the opportunity set is unchanged, there is no effect on naive cardinal freedom from interference, nor on diverse freedom from interference, but the policy might still affect evaluative freedom from interference since it changes relative prices. Some items a consumer might want are now out of their price range, so they have to purchase an alternative. This certainly affects the specific liberty of some individuals over some items, and, as we saw with evaluative freedom of choice, it might reduce the overall freedom of some people with respect to lunch. However, if healthy items are preferable overall for most people, Cafeteria Tax and Subsidize will increase the evaluative freedom from interference of people.

Cafeteria Healthier Menu does exclude items. It therefore removes the specific freedom of everyone to choose those items. If we assume that the default position is full freedom with respect to lunch, then Cafeteria Healthier Menu reduces the amount of negative freedom of all consumers since some items are excluded by Carolyn's fiat; thus, on ratio grounds, freedom from interference is reduced. This is certainly the case under naive cardinality freedom from interference. Carolyn might try to ensure that the healthy menu is more diverse than the original mixed one, and depending on that mix, the ratio of positive to negative items might increase freedom from interference. Evaluative freedom from interference is also a complex calculation. If we continue to assume that the healthy menu offers more highly valued items than the unhealthy one, then the healthy menu can offer fewer items yet increase evaluative freedom. This is also true even if that menu consists of only one item if it is valued highly enough over a large menu whose items provide little or negative value - a somewhat odd conclusion for freedom measurement. The Kramer ratio is bounded at 1 whenever everything possible is included. Hence, removing an item from the full set, no matter how little valued, will reduce liberty. However, no real cafe can offer all possible items; hence, replacing less valued items with more valued ones, even if lower in number, can increase the liberty ratio.

Overall, although Cafeteria Nudge is found to be liberty preserving according to the three primary metrics considered, Cafeteria Tax and Spend and Cafeteria Healthier Menu have been found to vary in whether they enhance, maintain or reduce liberty, depending on context. This means that in some cases, regulations will favour liberty more than nudges, while in other cases, they will not - and this is so even according to the measures of liberty favoured by nudge advocates themselves. The liberty comparison depends on the specific nudges and regulations under consideration. In the next section, we address objections that may arise when turning from toy examples to national-level regulations.

\section{Objections}

One response is that while regulation does not necessarily reduce liberty, nudges never or rarely reduce liberty. Since nudges nearly always preserve liberty while regulation has a variable effect on liberty, there may still be liberty reasons for thinking that nudges are superior. We do not think so. First, as we have shown, by some measures, regulation increases liberty. If our desire is to maximize liberty, then we cannot suppose a priori that nudges are superior. To respond that what is important about nudges is that they have no effect on liberty is to assume that liberty preservation is about specific liberties, not about overall liberty. That has to be argued. We earlier dismissed that claim on the grounds that we often remove specific liberties in order to increase overall liberty. We maintain that comparing nudges and regulation liberty-wise is an empirical and not an analytic or a priori matter. Secondly, we have avoided criticisms of nudges on the grounds that they do not respect individual autonomy, but in a full comparison of nudges versus regulation, these claims are important. Again, we cannot assume that regulation decreases liberty 
whereas nudges have no effect since for some sophisticated accounts of liberty, autonomy takes a central role. Thirdly, where interests are heterogenous, it is by no means assured that nudges are more liberty preserving than regulation. Regulation might reduce the overall liberty of some while increasing that of others. If nudges genuinely have no effect on liberty, that is to privilege the regulatory status quo and privilege those whose liberty is preserved over those for whom it can be enhanced. A small reduction in a given citizen's specific liberty to buy foods containing trans fats, for example, is not a sufficient reason to forgo policies increasing the overall liberty of numerous citizens through long-term increases in life expectancy and quality of life.

A second line of criticism is that the real world is more complex than our toy examples suggest. That is, of course, true. However, that only makes the calculations more complex. It does not show that nudges are advantageous liberty-wise. While governments do ban certain dangerous products and limit how others might be used, some proposed regulations either tax or limit those ingredients deemed unhealthy. Such regulations introduce supplementary issues concerning strategic action by producers, long-term changes in consumption patterns and feedback effects, as well as further complications concerning heterogeneous effects and the measurement of overall freedom.

Unlike the removal of unhealthy products in Cafeteria Healthier Menu, a ban on using an ingredient such as partially hydrogenated oil does not reduce the available menu of goods sold to consumers. The same is the case for limits on the total amount of added sugar or salt in consumer products. This is because food producers adapt by reformulating their products to comply with the new regulations. Sometimes, the resulting product will simply be a trans-fat-free, lowsodium, low-sugar or sugar-free version of the original product. More likely, the company will introduce new products meeting the requirements, aiming to capture a greater market share by appealing to key demographics. The effects on liberty depend on the precise ways in which consumers and producers respond to the regulations, both in the short and the long run.

Restrictions on additives are unlikely to reduce freedom of choice under the naive cardinality measure. However, they might affect the calculation of diverse and evaluative freedom of choice. Food manufacturers choose additives either to appeal to our tastes or to increase the longevity of products. If the goal is to appeal to our tastes, you might think that regulating them will reduce our subjective evaluation of the food. However, we cannot assume so. First, as noted earlier, we cannot assume that manufacturers will simply remove or reduce additives to comply with regulations. Secondly, our preferences for food are partly shaped by our previous dietary habits. Experimental evidence suggests that consuming higher levels of sugar leads individuals to have increased preferences for sweet products after even a short period of exposure (Liem and Degraaf 2004). The effects of reducing consumption of sugar and salt are still under investigation, but studies show that changes in diet correlate with changes in food preferences over time (Martin et al. 2011). While changes in the ingredients of familiar food products might reduce our enjoyment of them in the short term, the long-term effects depend on the product reformulation.

This second point is a problematic one for liberty calculations. One basic principle of negative freedom is that one cannot make oneself free by changing one's preferences (Berlin 1995a, 31). Therefore, it would seem that at the moment additives are taken away, people must become less free on evaluative freedom grounds, even if they come to adapt their preferences over time. Having said this, such adaptive preferences for food over time are not quite what Berlin had in mind when he said that one could not make oneself free by extinguishing preferences. Furthermore, given that these additives appeal to us because of our evolutionarily developed tastes, on the evaluative freedom measure, adding them would increase freedom. The evaluative measure, since it tracks preferences or utility, will tend to track whatever we prefer. This, of course, as we mentioned earlier, is one of the problems with such measures of freedom - they tend to degenerate into measures of utility or welfare. 
Finally, however, we must also take account of what people say they want. Most people say they prefer healthier foods to less healthy ones and support moves to regulate additives detrimental to health. Thus, we cannot conclude that regulating their use will affect freedom of choice by the subjective evaluation measure. Furthermore, the long-run effects may create a virtuous feedback loop. As regulations change the availability of healthy products and increase consumer awareness, producers develop healthier products in response and consumers adapt their consumption behaviour and demand more of these products, in turn, leading producers to compete and increase the availability of products with healthy characteristics. Halpern (2015, esp. ch. 7) documents similar feedback loops with respect to automobile safety and mobile phone security.

A similar analysis applies to diverse freedom of choice. Without any limits on additives, highsugar and high-sodium products end up converging in both taste and ingredients (the Hotelling effect mentioned earlier). By limiting the amount of added sugar or salt, regulators can lead producers to compete on different grounds and seek new forms of product differentiation. This can increase the diversity of products. Of course, the precise consequences require empirical investigation. Our conclusion is that one cannot simply assume that regulation reduces liberty under the freedom of choice interpretation under any of the extant ways of measuring freedom of choice. Rather, this is an empirical issue.

We dismissed the idea that coercion is involved in the private cafeteria scenarios on the grounds that the interventions are not wrong by Wertheimer's proposal prong, but at the state level, we cannot be so dismissive. We noted in Cafeteria Healthier Menu that only if the unhealthy menu is thought to be the morally correct baseline is Carolyn's directive coercive. In real markets, given the interests of food manufacturers, considering unhealthy food as the morally correct baseline seems implausible. This is particularly so when consumers say they prefer healthier food.

Finally, turning to real-world regulations also complicates the calculation of freedom from interference. Like Cafeteria Healthier Menu, limits on additives remove the specific freedom of everyone to choose items with higher additives, thereby reducing the amount of negative freedom of all consumers since, on ratio grounds, freedom from interference is reduced. Adding diversity to the measure of freedom from interference might change that assessment, and adding the evaluation of the alternative does. If we assume that the healthier alternatives that are on offer after implementing the new regulations are preferred to those actually on offer under the old regime, then the positive side of the evaluative freedom from interference calculation will mean that liberty has increased. How far these are outweighed, if at all, by the large number of potential foods that could have been offered if the additives restriction was not in place depends upon their number and difference in evaluations. Again, we do not claim that banning additives increases evaluative freedom from interference, but we do claim that it cannot be assumed that limiting additives to healthy levels reduces it.

So far, we have considered the overall freedom of individuals with regard to a specific opportunity set: in our key example, the food available in a workplace cafeteria; in the regulatory examples, the products available for sale in stores. However, the dietary choices that people make also impact their other opportunity sets. For example, eating healthier food will enable individuals to have more energy, lose less time and money to illness, and expand their opportunity set in the domains of work, family and leisure. A healthier diet will therefore increase individuals' freedom of choice overall (in all three variants), with similar knock-on effects on their overall negative liberty.

\section{Conclusion}

Proponents claim that nudging is a libertarian form of paternalism since it increases welfare without reducing liberty. Some have criticized nudges on the grounds that they can reduce liberty either they reduce positive liberty by manipulating citizens or they reduce republican liberty by 
imposing a form of 'alien control'. In this article, we have offered a method for more systematic comparisons between nudge and regulation in terms of negative freedom. When we consider the measurement of negative freedom, the simple libertarian claim for nudge is problematic. Even outside of any problems for autonomy, nudge is not necessarily more libertarian than regulation on negative liberty grounds. This conclusion has a number of important implications for our understanding of nudge, regulations and liberty.

First, rejecting the liberty advantage of nudges over regulations means that proponents of nudge concerned about negative liberty will either have to develop new arguments in defence of their position or shift towards preferring regulations, particularly when it comes to public health policies. Well-constructed regulations that limit which ingredients can be used in food manufacturing or that reduce the quantity of salt, sugar and other additives served in meals can enhance the freedom of choice of consumers more than nudges and should be further investigated as solutions in the fight against obesity-related health problems. Contrary to Thaler and Sunstein, there is no reason to be suspicious of mandates and bans as necessarily reducing liberty.

To the extent that nudge advocates wish to continue defending specific nudges, they will no longer be able to eschew the difficult conceptual and empirical questions involved in the measurement of liberty. We demonstrate that the measurement of liberty needs to be taken as seriously as the measurement of welfare. Our examples drawn from public health regulation provide an illustration that can be replicated across other domains. Instead of assuming that a given regulation reduces liberty, policymakers and political scientists ought to include liberty assessments analogous to the more commonly used cost-benefit analyses measuring welfare.

Secondly, our partial defence of regulations on negative liberty grounds clears the way for a more comprehensive defence. Although few scholars have systematically compared nudges with more traditional regulatory tools, some have begun to build the case that we should prefer regulations to nudges on positive liberty grounds (see, for example, Hausman and Welch 2010, 134-5). The same is true when it comes to republican liberty comparisons, where the preference for a given nudge or regulation will depend on the degree of popular control over the political processes resulting in the given policy (Schmidt 2017). Adding our negative liberty assessment to this literature gives us good reasons to believe that not only is there no $a$ priori ground to consider nudges as better for liberty than regulations, but regulations may also, in fact, turn out to be the more liberty-favouring solutions in multiple contexts. Investigating this stronger claim goes beyond the scope of this article (for further discussion of these issues, see Dowding and Oprea 2021).

Our article goes beyond the nudge debate to give liberal political theorists new arguments in favour of regulation. Traditional regulatory mechanisms have come under strain from libertarians, who generally prefer market mechanisms to any government action (Glaeser 2006; Rebonato 2014; White 2013). In response to these criticisms, some have come to the defence of government regulation by denying the moral significance of the liberty concerns (Conly 2013). Our article instead shows that the concern that government regulation necessarily reduces liberty is vastly overstated, particularly when it comes to negative liberty. Although the current article does not offer a systematic comparison between regulations and unregulated markets, it offers a series of liberty measurements that scholars can use to produce such comparisons without assuming an a priori liberty advantage on the side of markets.

Finally, our article provides a template for the normative assessment of policy tools. In doing so, it joins the growing interdisciplinary literature in politics, philosophy and economics engaging in empirically grounded, non-ideal political philosophy (Bovens 2009; Button 2018; Dowding 2020; Grant 2006). As an exercise in non-ideal theory, the article takes as its starting premise boundedly rational individuals navigating increasingly complex choice environments designed to steer them in directions that do not necessarily track their interests or their stable preferences. As the fifth section illustrated, the normative assessment of a given regulation involves attending to a range of empirical findings and strategic considerations. Although a given regulation may 
limit a specific liberty, assessing how the policy affects overall liberty involves more complex calculations of the kind we illustrate.

Acknowledgements. In addition to the editor and our anonymous reviewers, we would like to thank Will Bosworth, Simon Cotton, Nicholas Drake, Anne Gelling, Jasper Hedges, Ten-Herng Lai, Antong Liu, Lars Moen, Daniel J. Stephens, Jeff Spinner-Halev and Brad Taylor for their critical comments on the article, as well as PhD students at the ANU (Australian National University), MSPT (Moral, Social, and Political Theory) Graduate Seminar, especially Nicholas Drake, Christoph Lernpass, James Lim, Kirsten Mann, Oliver Rawle and Shang Long Yeo.

Financial Support. Keith Dowding was a (virtual) visiting fellow at the Centre for Advanced Study, Oslo, under the GOODPOL project (What is a Good Policy? Political Morality, Feasibility, and Democracy) during part of the writing of this article. Alexandra Oprea was a lecturer in the School of Politics and International Relations at the Australian National University during part of the writing of this article.

Competing Interests. None.

\section{References}

Anderson S (2011) Coercion. In Zalta EN (ed) Stanford Encyclopedia of Philosophy (Summer 2021 edn). Available from https://plato.stanford.edu/entries/coercion/

Arrow KJ (1995) A note on freedom and flexibility. In Basu K, Pattanaik P and Suzumura K (eds), Choice, Welfare and Development: A Festschrift in Honour of Amartya K. Sen. Oxford: Clarendon Press, pp. 7-16.

Austen-Smith D and Banks JS (1999) Positive Political Theory I. Ann Arbor, MI: University of Michigan Press.

Backholer K et al. (2016) The impact of a tax on sugar-sweetened beverages according to socio-economic position: a systematic review of the evidence. Public Health Nutrition 19(17), 3070-3084.

Berlin I (1995a) Introduction. In Henry H (ed.), Liberty: Incorporating Four Essays on Liberty. Oxford: Oxford University Press, pp. 3-54.

Berlin I (1995b) Two concepts of liberty. In Henry H (ed.), Liberty: Incorporating Four Essays on Liberty. Oxford: Oxford University Press, pp. 166-217.

Bervoets S and Gravel N (2007) Appraising diversity with an ordinal notion of similarity: an axiomatic approach. Mathematical Social Sciences 53(2), 259-273.

Bíró A (2015) Did the junk food tax make the Hungarians eat healthier? Food Policy 54(1), 107-115.

Bovens L (2009) The ethics of nudge. In Grüne-Yanoff T and Hansson SO (eds), Preference Change: Approaches from Philosophy, Economics and Psychology. Berlin: Springer, pp. 207-220.

Button ME (2018) Bounded rationality without bounded democracy: nudges, democratic citizenship, and pathways for building civic capacity. Perspectives on Politics 16(4), 1034-1052.

Caprio S (2012) Calories from soft drinks: do they matter? New England Journal of Medicine 367, 1462-1463.

Carter I (1999) A Measure of Freedom. Oxford: Oxford University Press.

Carter I (2021) Positive and negative liberty. In Zalta EN (ed.), Stanford Encyclopedia of Philosophy (Winter 2021 edn). Available from https://plato.stanford.edu/entries/liberty-positive-negative/

Conly S (2013) Against Autonomy: Justifying Coercive Paternalism. Cambridge: Cambridge University Press.

Dowding K (2020) It's the Government, Stupid: How Governments Blame Citizens for Their Own Policies. Bristol: Bristol University Press.

Dowding K and Oprea A (2021) Reconsidering Nudges and Manipulation. Unpublished manuscript. Available from https:// www.researchgate.net/publication/357227067_Reconsidering_Nudges_and_Manipulation. Last accessed December 30, 2021.

Dowding K and van Hees M (2009) Freedom of choice. In Anand P, Pattanaik P and Puppe C (eds), Oxford Handbook of Rational and Social Choice. Oxford: Oxford University Press, pp. 374-392.

Funk C and Kennedy B (2016) The New Food Fights: U.S. Public Divides over Food Science: Differing Views on Benefits and Risks of Organic Food, GMOs as Americans Report Higher Priority for Healthy Eating. Pew Research Center. Available from https:/www.agandruralleaders.org/sites/default/files/summit/handouts2017/The\%20New\%20Food\% 20Fights.pdf. Last accessed December 30, 2021.

Glaeser EL (2006) Paternalism and psychology. The University of Chicago Law Review 73(1), 133-156.

Goodwin T (2012) Why we should reject 'nudge'. Politics 32(2), 85-92.

Grant RW (2006) Ethics and incentives: a political approach. The American Political Science Review 100(1), 29-39.

Grummon AH et al. (2019) Designing better sugary drink taxes. Science 365(6457), 989-990.

Grüne-Yanoff T (2012) Old wine in new casks: libertarian paternalism still violates liberal principles. Social Choice and Welfare 38(4), 635-645.

Halpern D (2015) Inside the Nudge Unit: How Small Changes Can Make a Big Difference. Harmondsworth: Penguin. 
Hausman DM and Welch B (2010) To nudge or not to nudge? Journal of Political Philosophy 18(1), 123-136.

John P, Graham S and Stoker G (2009) Nudge, nudge, think, think: two strategies for changing civic behaviour. The Political Quarterly 80(3), 361-370.

Kramer MH (2003) The Quality of Freedom. Oxford: Oxford University Press.

Kreps DM (1979) A representation theorem for 'preference for flexibility'. Econometrica 47(3), 565-77.

Liem D and Degraaf C (2004) Sweet and sour preferences in young children and adults: role of repeated exposure. Physiology \& Behavior 83(3), 421-429.

Martin CB et al. (2018) Attempts to Lose Weight among Adults in the United States, 2013-2016. NCHS Data Brief No. 313. Hyattsville, MD: National Center for Health Statistics.

Martin CK et al. (2011) Change in food cravings, food preferences, and appetite during a low-carbohydrate and low-fat diet. Obesity Facts 19(10), 1963-1970.

National Conference of State Legislatures (no date) State Laws Related to Dietary Sodium. Available from https://www.ncsl. org/research/health/analysis-of-state-laws-related-to-dietary-sodium.aspx

Nehring K and Puppe C (2002) A theory of diversity. Econometrica 70(3), 1155-1198.

Nehring K and Puppe C (2009) Diversity. In Anand P, Pattanaik PK and Puppe C (eds), The Handbook of Rational and Social Choice. Oxford: Oxford University Press, pp. 298-320.

Nozick R (1969) Coercion. In Nozick R (ed.), Socratic Puzzles. Cambridge: Harvard University Press, pp. 15-44.

OECD (Organisation for Economic Co-operation and Development) (2017) Behavioural Insights and Public Policy: Lessons from around the World. Paris: OECD Publishing.

Pattanaik P and Xu Y (1990) On ranking opportunity sets in terms of freedom of choice. Recherches Economiques de Louvain 56, 383-390.

Pattanaik P and Xu Y (1998) On preference and freedom. Theory and Decision 44, 173-198.

Pattanaik P and Xu Y (2000) On diversity and freedom of choice. Mathematical Social Sciences 30, 123-130.

Prentice AM (2006) The emerging epidemic of obesity in developing countries. International Journal of Epidemiology 35(1), 93-99.

Rebonato R (2014) A critical assessment of libertarian paternalism. Journal of Consumer Policy 37(3), 357-396.

Rivlin G (2016) Rigged: Supermarket Shelves for Sale. Washington, DC: Center for Science in the Public Interest.

Schmidt AT (2017) The power to nudge. American Political Science Review 111(2), 404-417.

Schmidt LA (2014) New unsweetened truths about sugar. JAMA Internal Medicine 174(4), 525-526.

Sen A (2002) Rationality and Freedom. Cambridge, MA: Harvard University Press.

Steiner H (1983) How free: computing personal liberty. In Griffiths AP (ed.), Of Liberty. Cambridge: Cambridge University Press, pp. 73-89.

Steingoltz M, Picciola M and Wilson R (2018) Consumer health claims 3.0: the next generation of mindful food consumption. LEK Insights 20(51), 1-6. Available from https://www.lek.com/insights/ei/next-generation-mindful-food-consumption

Sturm R, An R and Patel D (2013) A cash-back rebate program for healthy food purchases in South Africa. American Journal of Preventive Medicine 44(6), 567-572.

Sunstein CR and Thaler RH (2003) Libertarian paternalism is not an oxymoron. University of Chicago Law Review 70(4), $1159-1202$.

Thaler RH and Sunstein CR (2003) Libertarian paternalism. American Economic Review: Papers and Proceedings 93(2), 175-179.

Thaler RH and Sunstein CR (2008) Nudge: Improving Decisions about Health, Wealth and Happiness. New Haven, CT: Yale University Press.

US Food and Drug Administration (2018) Final Determination Regarding Partially Hydrogenated Oils (Removing Trans Fat). Available from https://www.fda.gov/food/food-additives-petitions/final-determination-regarding-partially-hydrogenated-oils-removing-trans-fat. Last accessed December 30, 2021.

Van Hees M (2004) Freedom of choice and diversity of options: some difficulties. Social Choice and Welfare 22, 253-266.

Waldron J (2014) It's all for your own good. The New York Review of Books. Available from http://www.nybooks.com/articles/ archives/2014/oct/09/cass-sunstein-its-all-your-own-good/

Wertheimer A (1987) Coercion. Princeton, NJ: Princeton University Press.

White MD (2013) The Manipulation of Choice: Ethics and Libertarian Paternalism. New York, NY: Palgrave Macmillan.

WHO (World Health Organization) (2019) Replace Trans Fat: Policies to Eliminate Industrially Produced Trans Fat. Available from https://www.who.int/teams/nutrition-and-food-safety/replace-trans-fat. Last accessed December 30, 2021.

WHO (2020a) World Health Statistics 2020: Monitoring Health for the SDGs, Sustainable Development Goals. Available from https://www.who.int/publications/i/item/9789240005105. Last accessed December 30, 2021.

WHO (2020b) Obesity and Overweight. Available from https://www.who.int/news-room/fact-sheets/detail/obesity-and-overweight Wilkinson TM (2013) Nudging and manipulation. Political Studies 61(4), 341-355.

Cite this article: Dowding K, Oprea A (2023). Nudges, Regulations and Liberty. British Journal of Political Science $\mathbf{5 3}$ 204-220. https://doi.org/10.1017/S0007123421000685 